\title{
The Research of Portal Competition Based on Game Theory
}

\author{
Wang Ye \\ Tianjin Normal University \\ Tianjin, China \\ 65722066@qq.com \\ Zhu Yaqian \\ Tianjin Normal University \\ Tianjin, China \\ 728572687@qq.com
}

\author{
Wu Ting \\ Tianjin Normal University \\ Tianjin, China \\ 594329722@qq.com \\ Zhang Yu, Liu Yang \\ Tianjin Normal University \\ Tianjin, China \\ 654825235@qq.com
}

\begin{abstract}
Based on the theory of competition, social network analysis and the game theory, this thesis builds up the game model of portal competition analysis, studies the current status of portal competition from a new viewing angle, to add a new analytical tool and viewing angle for the research of portal competition and open the idea of competitive innovation for the entire portal industry.
\end{abstract}

Key words-Portal websites; Game theory; Social network analysis; Cournot model

With the rapid development of Internet, the homogeneity phenomenon in the development of portal websites also tends to be more obvious and expanding audience is restricted as well. In addition, due to the limitations of e-commerce development, major portal sites arrested development in the field of B2C which has a very high profit margin. It has a direct impact on the development of the portals. At present, the Internet enterprises should enhance the capacity of independent innovation through the technological innovation, find existing problems, timely adjust strategic goals, and improve the enterprises' core competitiveness.

\section{EMPIRICAL RESEARCH ON THE PORTAL COMPETITION}

The questionnaire survey was conducted among the comprehensive group on different channels of the portal and a total of 190 questionnaires were returned. According to the relationship between the preferred and the second choice, the questionnaire data was processed by eight channels, and get eight channels' relationship matrix. Each value in the matrix represents the number of the preferred and the secondary. In addition, the eight channels relationship matrix can be integrated into one relationship matrix, called "the integrated weighted channel". The average weighted on the score of the eight channels in ten major portals Tencent, Sina, Netease, Sohu, Phoenix, China, MSN, 21CN China, TOM and YAHOO (The score is set from 0 to 8,8 for the channel at top position, 1 for the last, and 0 for the channel which is not set). After the weight of each channel is obtained, as shown in Table 2.1, multiplied by each value of the corresponding channel matrix. Finally we can get a relationship matrix of comprehensive weighted channel. 
TABLE I . WEIGHT VALUES OF EIGHT CHANNEL

\begin{tabular}{|c|c|c|c|c|c|c|c|c|}
\hline & News & Video & Financial & Entertainment & Sports & Auto & Realestate & $\begin{array}{l}\text { Science and } \\
\text { technology }\end{array}$ \\
\hline Tencent & 8 & 4 & 7 & 5 & 6 & 2 & 1 & 3 \\
\hline Sina & 8 & 7 & 4 & 6 & 5 & 3 & 1 & 2 \\
\hline Netease & 8 & 7 & 4 & 5 & 6 & 3 & 1 & 2 \\
\hline Sohu & 8 & 7 & 5 & 4 & 6 & 3 & 2 & 1 \\
\hline Phoenix & 8 & 7 & 6 & 4 & 1 & 5 & 2 & 3 \\
\hline China & 8 & 0 & 7 & 5 & 3 & 6 & 0 & 4 \\
\hline $21 \mathrm{CN}$ & 8 & 0 & 7 & 6 & 5 & 4 & 3 & 0 \\
\hline MSN China & 8 & 1 & 5 & 7 & 6 & 3 & 4 & 2 \\
\hline TOM & 8 & 0 & 0 & 6 & 5 & 7 & 0 & 0 \\
\hline YАНОО & 8 & 0 & 6 & 7 & 5 & 4 & 0 & 3 \\
\hline Mean value & 8 & 3.3 & 5.1 & 5.5 & 4.8 & 4 & 1.4 & 2 \\
\hline Weight value & $23 \%$ & $10 \%$ & $15 \%$ & $16 \%$ & $14 \%$ & $12 \%$ & $4 \%$ & $6 \%$ \\
\hline
\end{tabular}

In this paper, we use the social network analysis method to analyze the questionnaire data, and use the Ucinet6.212 analysis software to deal with the relationship matrix, then we can get the competitive network graph of each channel, and the clustering results of each matrix.

A. Social Network Analysis of Channel
In this group, there are 10 channel relationship matrixes. Ucinet software is used to draw the competition network diagram of each matrix. This paper only lists the relationship matrix and the network diagram of the news channel and other channels of the matrix and the network graph theory are the same.

TABLE II . NEWS CHANNEL RELATION MATRIX

\begin{tabular}{|c|c|c|c|c|c|c|c|c|c|c|}
\hline $\begin{array}{c}\text { News } \\
\text { channel }\end{array}$ & Tencent & Sina & Netease & Sohu & Phoenix & China & $21 \mathrm{CN}$ & MSN China & TOM & YAHOO \\
\hline Tencent & 0 & 42 & 13 & 12 & 12 & 1 & 0 & 0 & 0 & 0 \\
\hline Sina & 19 & 0 & 10 & 10 & 8 & 0 & 0 & 1 & 0 & 0 \\
\hline Netease & 3 & 5 & 0 & 1 & 1 & 0 & 0 & 0 & 0 & 0 \\
\hline Sohu & 4 & 4 & 3 & 0 & 4 & 0 & 0 & 0 & 0 & 1 \\
\hline Phoenix & 10 & 12 & 7 & 4 & 0 & 1 & 0 & 0 & 0 & 0 \\
\hline China & 0 & 0 & 0 & 0 & 0 & 0 & 0 & 0 & 0 & 0 \\
\hline $21 \mathrm{CN}$ & 0 & 0 & 0 & 0 & 0 & 0 & 0 & 0 & 0 & 0 \\
\hline MSN China & 1 & 0 & 0 & 0 & 0 & 0 & 0 & 0 & 0 & 0 \\
\hline TOM & 0 & 0 & 0 & 0 & 0 & 0 & 0 & 0 & 0 & 0 \\
\hline YAHOO & 0 & 0 & 0 & 0 & 1 & 0 & 0 & 0 & 0 & 0 \\
\hline
\end{tabular}




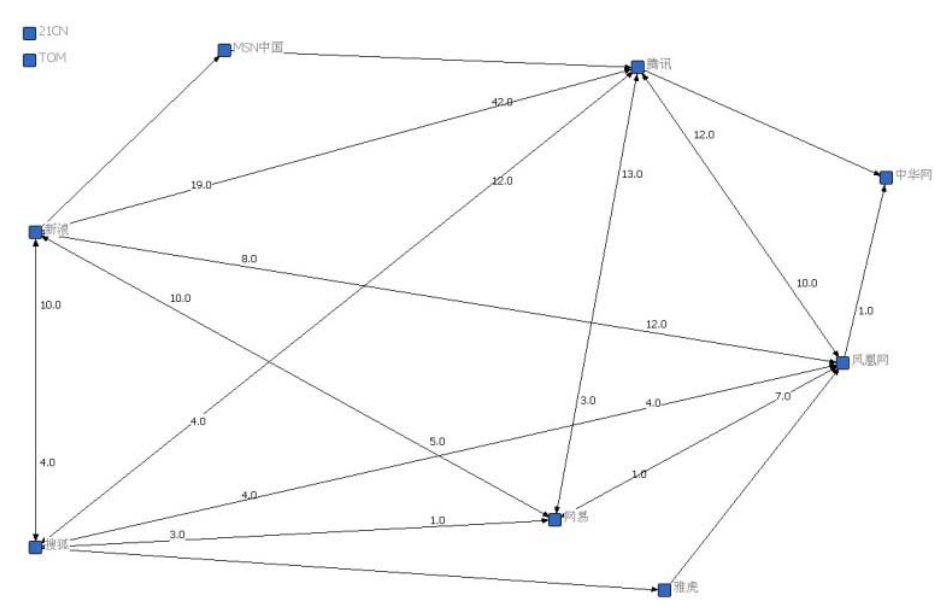

Fig.1. News channel network diagram

From Figure 1, in the news channel, Tencent and Sina are intimately connected and they are in keen competition. In addition, among Tencent, Sina, Netease, Sohu and Phoenix, there are a fair amount of associations and competitions. As for the Chinese network, MSN China and YAHOO, although these sites relate with the ones listed above, the association is few and it's hard to compete with them. $21 \mathrm{CN}$ and TOM are in a state of isolation, indicating that both of them have very few users and non-threatening at present.

\section{B. Clustering Results}

Through the further process of the 10 channels, the news channel, the video channel, the financial channel, the entertainment channel, the sports channel, the sports channel, the auto channel, the real estate channel, the science and technology channel, the integrated channel, and the comprehensive weighted channel, the clustering results are as follows:

TABLEIII. The Results of the Channel Clustering

\begin{tabular}{|c|c|c|c|c|c|c|}
\hline Channel & 1 & 2 & 3 & 4 & 5 & 6 \\
\hline news channel & $\begin{array}{l}\text { Tencen,Sina, } \\
\text { Sohu, Phoenix }\end{array}$ & Netease,China & MSN China & 21CN,TOM & YАНОО & \\
\hline video channel & $\begin{array}{c}\text { Tencent, Sina, } \\
\text { Netease }\end{array}$ & Sohu, Phoenix & China,TOM & $21 \mathrm{CN}$ & $\begin{array}{l}\text { MSN China, } \\
\text { YAHOO }\end{array}$ & \\
\hline financial channel & $\begin{array}{c}\text { Tencent,Phoeni } \\
\text { x }\end{array}$ & Netease & Sina,Sohu & China & 21CN,YAHOO & $\begin{array}{l}\text { MSN China, } \\
\text { TOM }\end{array}$ \\
\hline entertainment channel & $\begin{array}{c}\text { Tencent, } \\
\text { Sina,TOM }\end{array}$ & Phoenix & $\begin{array}{c}\text { Netease,Sohu, } \\
\text { MSN China }\end{array}$ & YAHOO & 21CN,China & \\
\hline sports channel & $\begin{array}{l}\text { Tencent, Sina, } \\
\text { Sohu }\end{array}$ & $\begin{array}{l}\text { Netease, } \\
\text { Phoenix }\end{array}$ & YAHOO & 21CN,China & $\begin{array}{c}\text { MSN } \\
\text { China,TOM }\end{array}$ & \\
\hline auto channel & $\begin{array}{l}\text { Tencent, } \\
\text { Phoenix }\end{array}$ & $\begin{array}{l}\text { Sina, Netease, } \\
\text { Sohu }\end{array}$ & $\begin{array}{c}\text { China, } \\
\text { MSN China }\end{array}$ & 21CN,YAHOO & TOM & \\
\hline real estate channel & Tencent, Sina & Netease & Sohu, Phoenix & YAHOO & 21CN,China & $\begin{array}{l}\text { MSN China, } \\
\text { TOM }\end{array}$ \\
\hline science and technology channel & $\begin{array}{c}\text { Tencent, Sina, } \\
\text { Netease }\end{array}$ & Phoenix & $\begin{array}{c}\text { Sina, } \\
\text { YAHOO }\end{array}$ & China & 21CN,TOM & MSN China \\
\hline integrated channel & $\begin{array}{c}\text { Tencent,Phoeni } \\
\text { x,YAHOO }\end{array}$ & $21 \mathrm{CN}$ & $\begin{array}{c}\text { Sina, Netease, } \\
\text { Sohu }\end{array}$ & China & $\begin{array}{c}\text { MSN } \\
\text { China,TOM }\end{array}$ & \\
\hline comprehensive weighted channel & $\begin{array}{c}\text { Tencent, Sina, } \\
\text { Netease, Sohu, } \\
\text { Phoenix }\end{array}$ & MSN China & TOM & $\begin{array}{l}\text { China, } \\
\text { YAHOO }\end{array}$ & $21 \mathrm{CN}$ & \\
\hline
\end{tabular}




\section{GAME STUDY OF THE PORTAL WEBSITES COMPETITION'S COURNOT MODEL}

This paper uses game theory of Cournot model to analyze the portal websites competition. The clustering results on the news channel, video channel, financial channel, entertainment channel, sports channel, auto channel, real estate channel, science and technology channel, integrated channel, and the comprehensive weighted channel are used as a game player of the Cournot model and the number of the clusters is the number of the game players. Set the basic assumptions, the basic variables and build up revenue function, calculate the income of each player by simultaneous equations. The total sample size of the group is 190 . The basic assumption is that the ten portals studied in this paper take the same measure according to the strategy and have no fixed costs, only a marginal cost of every one unit increment of inputs. In addition, the assumption emphasizes that all of the portals decide the inputs at the same time.

According to the size of the total number of the Preferred times, the marginal cost of each portal (Tencent, Sina, Netease, Sohu, Phoenix, CDC, 21CN, MSN China, TOM and Yahoo)strategy investment is assumed respectively as follow:

$$
c_{10}=1, c_{11}=2, c_{12}=5, c_{13}=3, c_{14}=4, c_{15}=6, c_{16}=9, c_{17}=7, c_{18}=10, c_{19}=8
$$

Since each player is made by one or more portals, this thesis takes the biggest marginal cost among the portals as the marginal cost from each player. Assuming that each player improves their own competitiveness with a series of similar measures, the inputs of these measures are respectively , and the yield of per unit of input is

$$
P_{1}=N-\sum_{j=1}^{n} q_{1 j}
$$

( $\mathrm{N}$ is the number for samples of the group, $\mathrm{n}$ is clustering number for each channel of the group).

\section{A. News Channel}

Set each player to improve their own competitiveness by taking the "information release in time" strategy and making a series of the same measures, The input of these measures are respectively $q_{11}, q_{12}, q_{13}, q_{14}, q_{15}$, yield per unit of input is

$$
p_{1}=190-\left(q_{11}+q_{12}+q_{13}+q_{14}+q_{15}\right),
$$

As well as the marginal cost of the news channel's game player 1 ,game player 2 ,game player 3 ,game player 4 ,game player 5 is respectively:

$$
K_{11}=c_{14}=1, K_{12}=c_{15}=6, K_{13}=c_{17}=7, K_{14}=c_{18}=10, K_{15}=c_{19}=8,
$$

Thus, the revenue equation for each player is as follows:

$$
\begin{aligned}
& u_{11}=q_{11}\left(P_{1}-K_{11}\right)=186 q_{11}-q_{11}{ }^{2}-q_{11} q_{12}-q_{11} q_{13}-q_{11} q_{14}-q_{11} q_{15} ; \\
& u_{12}=q_{12}\left(P_{1}-K_{12}\right)=184 q_{12}-q_{12}{ }^{2}-q_{11} q_{12}-q_{12} q_{13}-q_{12} q_{14}-q_{12} q_{15} ; \\
& u_{13}=q_{13}\left(P_{1}-K_{13}\right)=183 q_{13}-q_{13}{ }^{2}-q_{11} q_{13}-q_{12} q_{13}-q_{13} q_{14}-q_{13} q_{15} ; \\
& u_{14}=q_{14}\left(P_{1}-K_{14}\right)=180 q_{14}-q_{14}{ }^{2}-q_{11} q_{14}-q_{12} q_{14}-q_{13} q_{14}-q_{14} q_{15} ; \\
& u_{15}=q_{15}\left(P_{1}-K_{15}\right)=182 q_{15}-q_{15}{ }^{2}-q_{11} q_{15}-q_{12} q_{15}-q_{13} q_{15}-q_{14} q_{15} ;
\end{aligned}
$$

The strategy $\left(q_{11}^{*}, q_{12}^{*}, q_{13}^{*}, q_{14}^{*}\right)$ can make the best interest of each game player if the $q_{11}^{*}, q_{12}^{*}, q_{13}^{*} 、 q_{14}^{*}$ is the best strategy for each other, and also it consists a Nash equilibrium. According to the definition of Nash equilibrium, Nash equilibrium is a strategy combination of optimal strategies for each game player. Therefore, if the strategy combination $\left(q_{11}^{*}, q_{12}^{*}, q_{13}^{*}, q_{14}^{*}\right)$ is the Nash equilibrium of this game, the solution $\left(q_{11}^{*}, q_{12}^{*}, q_{13}^{*}, q_{14}^{*}\right)$ must be the maximum value of the equation. The above four equations are first-order derivation and simultaneous equations:

$$
\begin{aligned}
& q_{11}=34, q_{12}=32, q_{13}=31, q_{14}=28, q_{15}=30, \quad P_{1}=35 \\
& u_{11}=1054, u_{12}=928, u_{13}=868, u_{14}=700, u_{15}=810
\end{aligned}
$$

So the strategy combination $(34,32,31,28,30)$ is the only Nash equilibrium in this game, and also the result of this game. The overall yield is 4360 .

\section{B. Video Channel}

Set each player taking the "content" of the strategy, the corresponding solution method and content in the same way. Therefore, the strategy combination $(33,34,28,29,30)$ is the only Nash equilibrium of the game, and also the result of the game. The overall yield is 4462 .

\section{Financial Channel}

Set each player taking the "content" of the strategy, the corresponding solution method and content in the same way. Therefore, the strategy combination $(28,27,29,26,23$, 22 ) is the only Nash equilibrium of the game, and also the result of the game. The overall yield is 4508 .

\section{Entertainment Channel}

Set each player taking e the "content" of the strategy, the corresponding solution method and content in the same way. Therefore, the strategy combination $(28,34,31,30,29)$ 
is the only Nash equilibrium of the game, and also the result of the game. The overall yield is 4642 .

\section{E. Sports Channel}

Set each player taking the "content" of the strategy, the corresponding solution method and content in the same way. Therefore, the strategy combination (35, 33, 30, 29, 28) is the only Nash equilibrium of the game, and also the result of the game. The overall yield is 4374 .

\section{F. Auto Channel}

Set each player taking the "content" of the strategy, the corresponding solution method and content in the same way. Therefore, the strategy combination (34, 33, 31, 29, 28) is the only Nash equilibrium of the game,and also the result of the game. The overall yield is 4366 .

\section{G. Real Estate Channel}

Set each player taking the "content" of the strategy, the corresponding solution method and content in the same way. Therefore, the strategy combination (31, 28, 29, 25, 24, 23 ) is the only Nash equilibrium of the game, and also the result of the game. The overall yield is 3836 .

\section{H. Science andTechnology Channel}

Set each player taking the "content" of the strategy, the corresponding solution method and content in the same way. Therefore, the strategy combination $(28,29,25,27,23$, 26 ) is the only Nash equilibrium of the game, and also the result of the game. The overall yield is 4026 .

\section{Integrated Channel}

Set each game to take the "content" of the strategy, the corresponding solution method and content in the same way. Therefore, the strategy combination (33, 31, 28, 30, 29) is the only Nash equilibrium of the game, but also the result of the game, the overall yield is 4726 .

\section{J. Integrated Weighted Channel}

Set each game to take the "content" of the strategy, the corresponding solution method and content in the same way. Therefore, the strategy combination (33, 31, 28, 30, 29) is the only Nash equilibrium of the game, but also the result of the game, the overall yield is 4726 .

\section{GAME COMPETITION ANALYSIS OF PORTAL WEBSITE}

In this group, the yield of the integrated weighted channel (4726) is the highest, followed by entertainment channel (4642) and integrated channel (4638). It reflects that most of the Internet users are concerned about the hot information, including entertainment information and other kinds of comprehensive information. At the same time, the comprehensive weighted channel, entertainment channel and integrated channel take measures on contents. The portal site should enhance the comprehensiveness and richness of content. In this group, Sohu's total earnings are the largest one(9862)followed by Phoenix (9798), Sina (9578), Tencent (9549), the least yield is TOM (6024).

In the news channel, Tencent, Sina, Sohu, phoenix net income is the highest $(1054,1054,1054,1054)$; in the video channel, Sohu and phoenix net income is the highest $(1088,1088) ;$ in the financial channel, Sina and Sohu's revenue is the highest $(928,928)$; in the entertainment channel, the highest return is Phoenix (1156); in the sports channel, Tencent, Sina and Sohu's revenue is the highes(1120,1120,1120); in the auto channel, Tencent, phoenix net income of the highest $(1054,1054)$; in the real estate channel, Tencent, Sina's revenue is the highest $(868,868)$; in the science and technology channel, phoenix net income is the highest (812); in the integrated channel, Sina, Netease, Sohu's earnings are the highest (1089,1089,1089);in the Comprehensive weighted channel, Tencent, Sina, Netease, Sohu, phoenix net income of the highest (1122,1122,1122,1122,1122).

\section{CONCLUSION}

Firstly, the Internet users are mostly concerned about the news, video, entertainment, science and technology. In these several aspects, Tencent, Sina, Netease, Sohu and phoenix do better and gain higher income in the game. As our country's three major portals, Sina, Netease and Sohu are still in development, but they still have a long way to go while comparing with Tencent and Phoenix.

Secondly, Chinese portals experienced the money burning era, the profitable stage and now the transition stage. In the process of the development, many sites are eliminated, leaving only a number of influential portals. However, the competitions are still fierce and the competition landscape also presents new characteristics and trends. In view of the huge demand of the information 
society, the network information is numerous and varied, and the development strategy of the portal website includes four aspects: first is to create excellent corporate culture and to train outstanding professionals to improve the competitiveness of the portal, second is to use the news influence for expanding the scale of users; third is to establish a professional and characteristic portal; fourth is to create differentiated services by the application of new technologies.

\section{ACKNOWLEDGMENT}

This work was supported by the project of technology development strategy research in Tianjin (no.14ZLZLZF0007).

\section{REFERENCES}

[1] Wu Chunjing . The present situation and Development Countermeasures of the portal websites in China $[\mathrm{J}]$. Popular science and technology, 2011 (5) : pp.42-43.
[2] Chen Changbin. The brand building and model construction of the domestic portal website -- a comparative study of the domestic and international portal $[\mathrm{J}]$. Enterprise energy, 2011 ( 10 ) : pp.18-19.

[3] Chen Lijie, Xiao Huilian, Chen Wenfu. The standard analysis of the four big portal website business model [J]. Journal of

[4] Zhanjiang Normal University,2010 (2) : pp.36-37.

[5] Wang Tingting, Li Yimin. Research on the profitability and development potential of the main business of the portal website [J]. Modern commercial industry,2010（23）: pp.40-41

[6] He Shounan. Logical analysis of incomplete information game [J]. Journal of Zhoukou Normal University,2010 (4) : pp.62-63.

[7] Bi Chenfei. China's online game firms Cournot model horizontal merger and alliance based on Optimization [J]. Journal of Harbin University of Commerce (SOCIAL SCIENCE EDITION),2008 (4) : pp.34-35.

[8] Liu Jun. Whole network analysis [M] Shanghai: Science Press, 2009.

[9] Luo Jiade. Social network analysis notes [M]. Beijing: Social Science Literature Press, 2010

[10] Michael Rappa (2007), “Business Model on the web” [J], Journal of Service Research, 13(7), 124-131.

[11] Ballester, C., Calvo-Armengol, A., Zenou, Y (2006), "Who's who in networks wanted: the key player" [J], Econometrics, 74(5), 1403-1417. 